\title{
Calculating Energy Consumption of Motor Systems with Varying Load using Iso Efficiency Contours
}

\author{
Dirk Vanhooydonck, Wim Symens, Wim Deprez, Joris Lemmens, Kurt Stockman, Steve Dereyne
}

\begin{abstract}
Increasing awareness of ecological problems forces machine manufacturers to design greener machines. This implies amongst other things the selection of the most efficient electric motor system for their specific application. On the other hand, machine building applications evolve more and more from constant speed and load characteristics to varying speed and load applications. Therefore, the motor system that is used evolves more and more from direct online (DOL) to motors fed by a variable speed drive (VSD). However, current efficiency standardization focuses on DOL applications, and can by consequence not offer assistance to the machine builder to select the most efficient motor-VSD combination for his particular varying load application. The goal of this paper is to present a methodology that allows to predict the energy consumption for a specific motor-VSD combination and a specific varying speed-load application, using the fairly new concept of iso efficiency contours. By comparing the predicted energy consumption for a number of selected combinations, the most efficient one is revealed.
\end{abstract}

Index Terms - Variable Speed Drives, Varying Load, Efficiency, Iso Efficiency Contours

\section{INTRODUCTION}

$\mathrm{G}_{\mathrm{i}}$ ROWING awareness of environmental issues leads to increased social pressure to reduce energy consumption in as many sectors as possible. This pressure affects also the machine building sector and pushes it towards the development of more ecological or "green" machines that are supposed to consume considerably less energy than their predecessors. Moreover, a machine builder who can prove that his machine has a lower "total cost of ownership" because of its decreased energy consumption, possesses a serious competitive advantage.

A substantial part of the energy consumption of machines in general is electrical energy. This is to a large extent due to the electrical motor systems they commonly employ. Electrical motor-driven systems account for roughly $50 \%$ of the total electricity demand today, and approximately $65 \%$ of the electricity used in industry is consumed by electrical motors [2]-[3], the majority of which are induction motors. Therefore, machine builders are nowadays confronted with the design question: "what would be the most efficient electrical motor system for my application?"

The fact is, however, that more and more of those

This work was partly supported by the Flemish Government (IWT), grant IWT80144

D. Vanhooydonck and W. Symens are with Flanders' Mechatronics Technology Centre (FMTC), Celestijnenlaan 300D, 3001 Leuven, Belgium (e-mail: dirk.vanhooydonck@fmtc.be and wim.symens@fmtc.be).

W. Deprez and J. Lemmens are with Katholieke Universiteit Leuven, Dept. Electrical Engineering (ESAT), Div. ELECTA, Kasteelpark Arenberg 10, 3001 Heverlee, Belgium (e-mail: wim.deprez@esat.kuleuven.be and joris.lemmens@esat.kuleuven.be).

K. Stockman and S. Dereyne are with Technical University College of West-Flanders, Graaf Karel de Goedelaan 5, Kortrijk 8500, Belgium and Department of Electrical Energy, Systems and Automation, Ghent University, Gent 9000, Belgium (e-mail: kurt.stockman@howest.be). applications are not constant speed applications, but a variable speed output at the motor shaft might be required during operation, either continuously and dynamically varying (e.g. in hybrid cars), or as a sequence of different stationary speed set points (e.g. in washing machines). Next to that, the load torque might also be varying. Accurate control of motor speed and torque is therefore required and variable speed drives (VSD's) are increasingly used to facilitate this control. Moreover, certain motor types like permanent magnet synchronous motors (PMSM's) or switched reluctance motors (SRM's) inherently require power electronic converters for their operation, and start to penetrate the market as well.

This means, however, that classical motor efficiency standards, like the IEC Std 60034-2-1 for efficiency measurement and the IEC Std 60034-30 for efficiency classification, cannot be used anymore by machine manufacturers for the selection of the most efficient electrical motor system (i.e. motor and VSD), since these standards have been developed for direct-online applications and only deal with efficiency values at rated speed and load.

This paper describes an approach, developed jointly by three collaborating research institutes, to tackle the question: "Given the required time-varying output speed and torque (at the motor shaft) of my application, and given a number of different optional motor-VSD combinations, which combination is the most efficient one?"

In order to provide an answer to this question, the proposed approach specifies how to calculate, for a specific motor-VSD combination, a prediction of the energy consumption during the specific torque-speed trajectory that is required by the application. By doing so for each optional combination and by comparing the predicted consumptions, the most efficient combination is revealed.

For the calculation of the consumed energy, the proposed approach uses the concept of iso efficiency contours (also labeled as "efficiency maps"). This concept is fairly new in the area of electrical motors. Its purpose is to characterize a motor system's efficiency in the full operating range (i.e. at different torque-speed load points). As mentioned before, standardization is still lacking here, but one of the goals of the larger research project that encompasses this paper, is to contribute to the motivation for this standardization.

For that reason and to set the stage for the remainder of this paper, section II starts with a concise description of the concept of iso efficiency contours in the field of electrical motor systems. Afterwards, section II will continue with an explanation of the proposed approach to predict energy consumption, using these contours. Sections III and IV report on two sets of measurements that have been performed to evaluate the proposed approach: section III treats measurements for a continuously time-varying torquespeed trajectory, whereas section IV deals with 
measurements for a torque-speed output trajectory that consists of a sequence of separate torque-speed set points.

\section{METHODOLOGY FOR ESTIMATION OF THE ENERGY CONSUMPTION USING ISO EFFICIENCY CONTOURS}

\section{A. Iso Efficiency Contours or Efficiency Maps}

The concept of iso efficiency contours is fairly new in the field of electrical motor systems, but has already a history in other fields, with other types of actuation and energy conversion. They are, for instance, used in combustion motor technology to describe the ratio of produced mechanical power and consumed fuel $([\mathrm{kWh} / \mathrm{g}])$ as a function of engine speed and torque (i.e. for the full $2 \mathrm{D}$ operating area). They also appear in hydraulics, to characterize, for example, the efficiency of pumps (ratio of produced hydraulic output power and mechanical input power) as a function of pressure and speed.

In the context of electrical motors, efficiency maps have already been used for the drive train design of electrical and hybrid cars [1]-[4]. Outside this area, however, the usage is limited, although its usefulness can be significant in the broader machine building industry, due to the increasing amount of variable speed-torque applications. For that reason, a joint research project was set up dealing with iso efficiency contours for electrical motor-VSD combinations. The main goals of this research project are: (1) a conceptual exploration of the contours and methods to measure them, (2) comparing the contours for different motors and motor types, and (3) checking the feasibility of using these contours to predict electrical energy consumption during an application with time-varying speed and torque. The outcome of this project is also hoped to contribute to the motivation for standardization of electrical motor system efficiencies for the full torque-speed operating range.

The third project goal above is the topic of this paper and will be treated further on, starting from the next paragraph (B.). The first and second project goal and the corresponding results are detailed in two other papers that have been submitted to this conference, respectively [5] and [6].

Fig. 1 shows an example of an iso efficiency contour that was measured in the framework of the project. It pictures the contour for a commercial $7.5 \mathrm{~kW}$ induction motor (IE2) with a commercial VSD in scalar mode. The efficiency is depicted as a function of the mechanical quantities, being motor speed and torque, and shows for each pair of those the corresponding efficiency of the electrical motor system. The efficiency is defined as the ratio of mechanical output power at the motor shaft and electrical input power going in the VSD, when the system is in motor operation and vice versa when the system is in generator operation. In Fig. 1, the first quadrant is shown, illustrating the efficiency in motor operation. The second and fourth quadrant can be used when the efficiency in generator operation is also required. The efficiency contour has been acquired by selecting a dense grid of torque-speed pairs in the full operating range and by measuring the ratio of mechanical and electrical power in each of these load points in static conditions (i.e. keeping torque and speed constant for some time). The upper boundaries are determined by peak torque (under rated speed) and peak power (above rated speed), while the full line indicates nominal torque $(49 \mathrm{Nm})$ and power $(7.5 \mathrm{~kW})$.

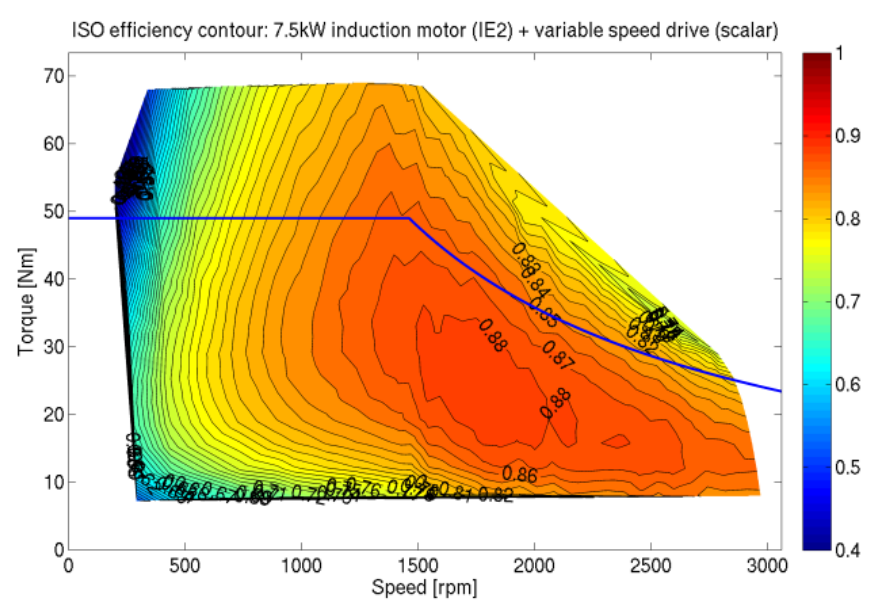

Fig. 1. Example of an iso efficiency contour for a commercial $7.5 \mathrm{~kW}$ induction motor (rated speed 1500rpm), with a commercial variable speed drive in scalar mode. Efficiency values can vary between 0 and 1 .

For more detailed information on the concept of efficiency maps for electrical motor systems and on the measurement procedure, and for more examples and comparisons, we refer again to [5] and [6].

\section{B. Prediction of the consumed energy during a time varying torque-speed trajectory}

We use the terminology "a time varying torque-speed trajectory" or "time varying load trajectory" to indicate a mathematical or numerical description of the variation over time of the required speed and the torque at the motor shaft, during operation. Hence, this variation can be plotted as a "trajectory" in the 2D torque-speed space. Two types of trajectories are considered here: (1) those with continuously varying torque and speed, and (2) sequences of different (stationary) speed-torque set points.

In order to predict the total consumption of electrical energy during such a trajectory, iso efficiency contours can be considered as a useful tool, as they show the motor system efficiency for the $2 \mathrm{D}$ torque-speed space. The proposed methodology is illustrated in Fig. 2 for an arbitrary (periodic) continuous trajectory and an arbitrary motor-VSD combination:

- Knowledge of the mechanical variables speed $(\omega)$ and torque $(T)$ at any moment in time along the trajectory implies that also the required mechanical output power $\left(P_{\text {mech }}\right)$ is known at each moment in time;

- Projecting the trajectory on the iso efficiency contour reveals the instantaneous efficiency $(\eta)$ of this motorVSD combination at any moment in time along the specified trajectory;

- By consequence, the instantaneous electrical power consumption at the input of the VSD $\left(P_{\text {elec }}\right)$ at any moment in time can be calculated as:

$$
P_{\text {elec }}(t)=\frac{P_{\text {mech }}(t)}{\eta(T, \omega)}=\frac{T(t) \cdot \omega(t)}{\eta(T, \omega)}
$$

when the system is in motor operation, or as:

$$
P_{\text {elec }}(t)=P_{\text {mech }}(t) \cdot \eta(T, \omega)
$$

when the system is in generator operation (both $P_{\text {elec }}$ and $P_{\text {mech }}$ are negative then). 
- The total electrical energy consumption $\left(E_{\text {elec }}\right)$ during the trajectory between $t_{\text {start }}$ and $t_{\text {end }}$ can then be calculated (or predicted) as:

$$
E_{\text {elec }}=\int_{t_{\text {start }}}^{t_{\text {end }}} P_{\text {elec }} d t=\int_{t_{\text {start }}}^{t_{\text {end }}} \frac{T(t) \cdot \omega(t)}{\eta(T, \omega)} d t
$$

in case of a continuously varying trajectory, or as:

$$
E_{\text {elec }}=\sum_{i} P_{\text {elec }_{i}} \cdot \Delta t_{i}=\sum_{i} \frac{T_{i} \cdot \omega_{i}}{\eta\left(T_{i}, \omega_{i}\right)} \Delta t_{i}
$$

when the trajectory consists of a sequence of stationary set points, where $\Delta t_{i}$ indicates the amount of time that the motor system is operating in the corresponding set point $\left(T_{i}, \omega_{i}\right)$. Remark that equations (3) and (4) are written, assuming that the system is in motor operation during the whole trajectory, using equation (1) to describe $P_{\text {elec }}$. If there are also parts where the system is in generator operation, equation (2) has to be used to describe $P_{\text {elec }}$ for these parts.
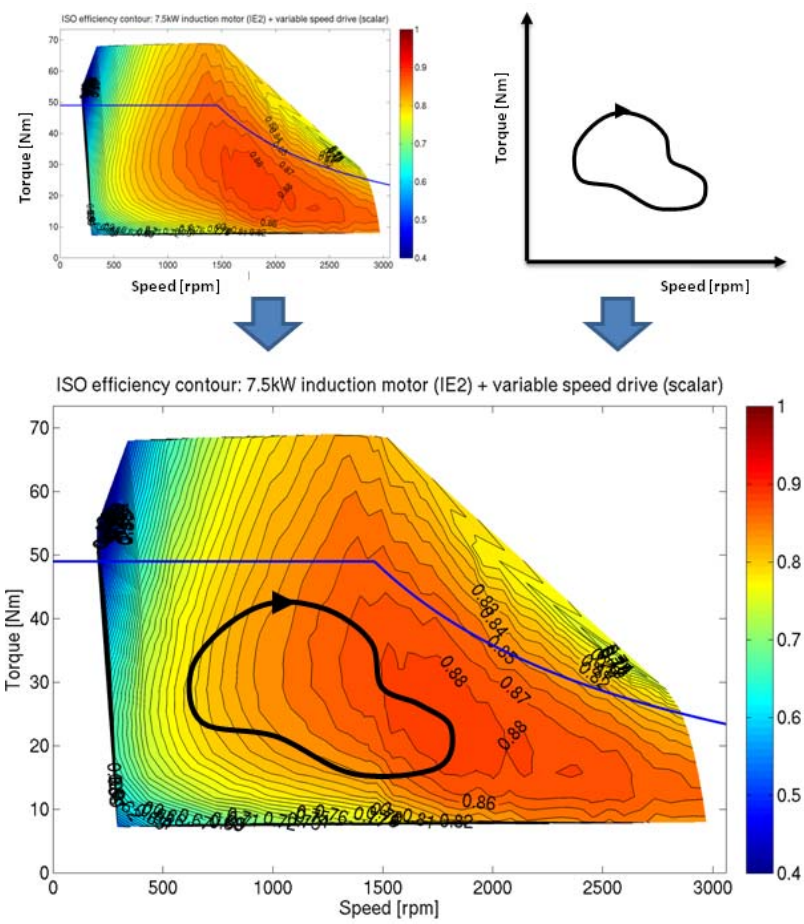

Fig. 2. Illustration of the procedure to calculate the electrical energy consumption of a specific motor system (motor and VSD) during a specific trajectory, using (1) the motor system's efficiency contour (upper left) and (2) the knowledge of the properties of the trajectory (upper right).

Next to the total electrical power consumption, also the average efficiency can be calculated for a certain motor system and a certain trajectory. This average efficiency is defined as the ratio of the total required mechanical power and the total consumed electrical power:

$$
\eta_{\text {avg }}=\frac{E_{\text {mech }}}{E_{\text {elec }}}
$$

where the total electrical energy can be calculated as shown in (2) or (3) and the mechanical energy can be calculated as:

$$
E_{\text {mech }}=\int_{t_{\text {start }}}^{t_{\text {end }}} P_{\text {mech }} d t=\int_{t_{\text {start }}}^{t_{\text {end }}} T(t) \cdot \omega(t) d t
$$

for the continuously varying trajectories, and as:

$$
E_{\text {mech }}=\sum_{i} P_{\text {mech }_{i}} \cdot \Delta t_{i}=\sum_{i} T_{i} \cdot \omega_{i} \cdot \Delta t_{i}
$$

for a sequence of stationary set points.

To determine which motor system (motor and VSD), given a varying load trajectory, is the most efficient one from a number of options, one can compare either the predicted electrical energy consumption for each motor system, or the average efficiency (as the mechanical energy is a constant for a certain trajectory).

In order to verify the methodology, two parallel measurement campaigns were set up by the research institutes involved in this project. The goal of both campaigns was to compare the predicted energy consumption with the measured one, given a motor system for which the iso efficiency contour is known (i.e. measured) and given the knowledge of the load trajectory (that can be applied to the motor on a test bench). The first measurement campaign deals with continuously varying load trajectories and is reported on in section III. Section IV discusses the second measurement campaign, which focused on trajectories that consist of sequences of discrete load points. One of the questions that needed to be answered is how accurate the prediction methodology is for a continuously varying trajectory, given the fact that the iso efficiency contours have been measured in stationary conditions.

\section{VERIFICATION FOR CONTINUOUSLY VARYING TRAJECTORIES}

\section{A. Measurement setup}

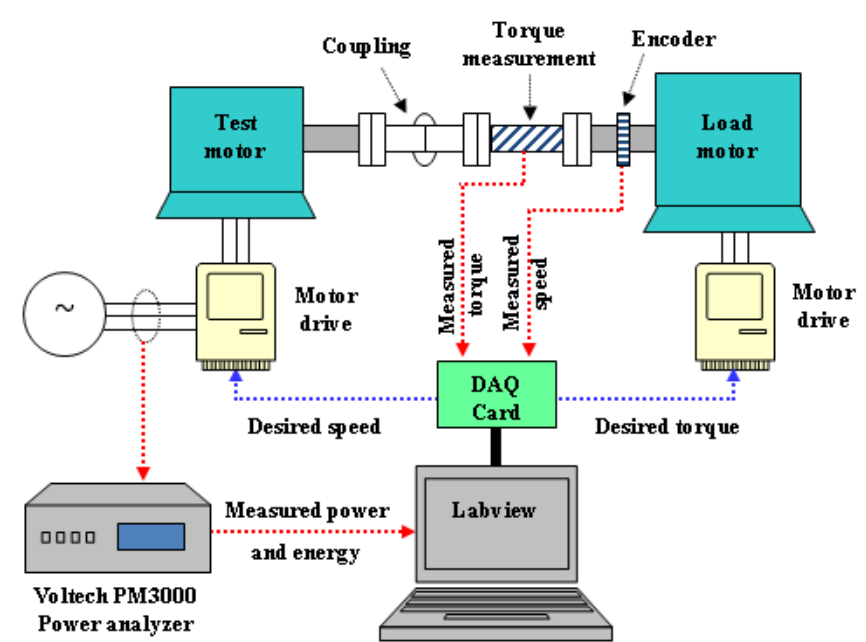

Fig. 3. Setup to measure the consumption of electrical energy of a motor system, during an applied torque-speed trajectory.

The measurements in this campaign have been performed on the motor system with iso efficiency contour shown in Fig. 1. This motor system was installed on a test bench as shown in Fig. 3. The torque speed trajectory is applied to the test motor system by sending the time-varying speed demand to the test motor drive and the time-varying load torque demand to the load motor drive. The electrical power and energy consumption is measured by a power analyzer, while torque and speed measurements provide the delivered mechanical power and energy. 
Test trajectories have been selected that cross a big span of the torque-speed operating range, and that are periodic, so the consumed energy can be measured over several periods (and averaged if needed). The chosen torque and speed are sinusoidal functions of time, with different frequencies, resulting in "Lissajous-shaped" curves in the 2D torquespeed space, as illustrated with an example in Fig. 4. Several measurements have been performed, with different frequencies for torque and speed, so different Lissajous curves are created, and less or more dynamical trajectories are obtained respectively by lower and higher frequencies. Results will be reported in section $\mathrm{E}$ further on.
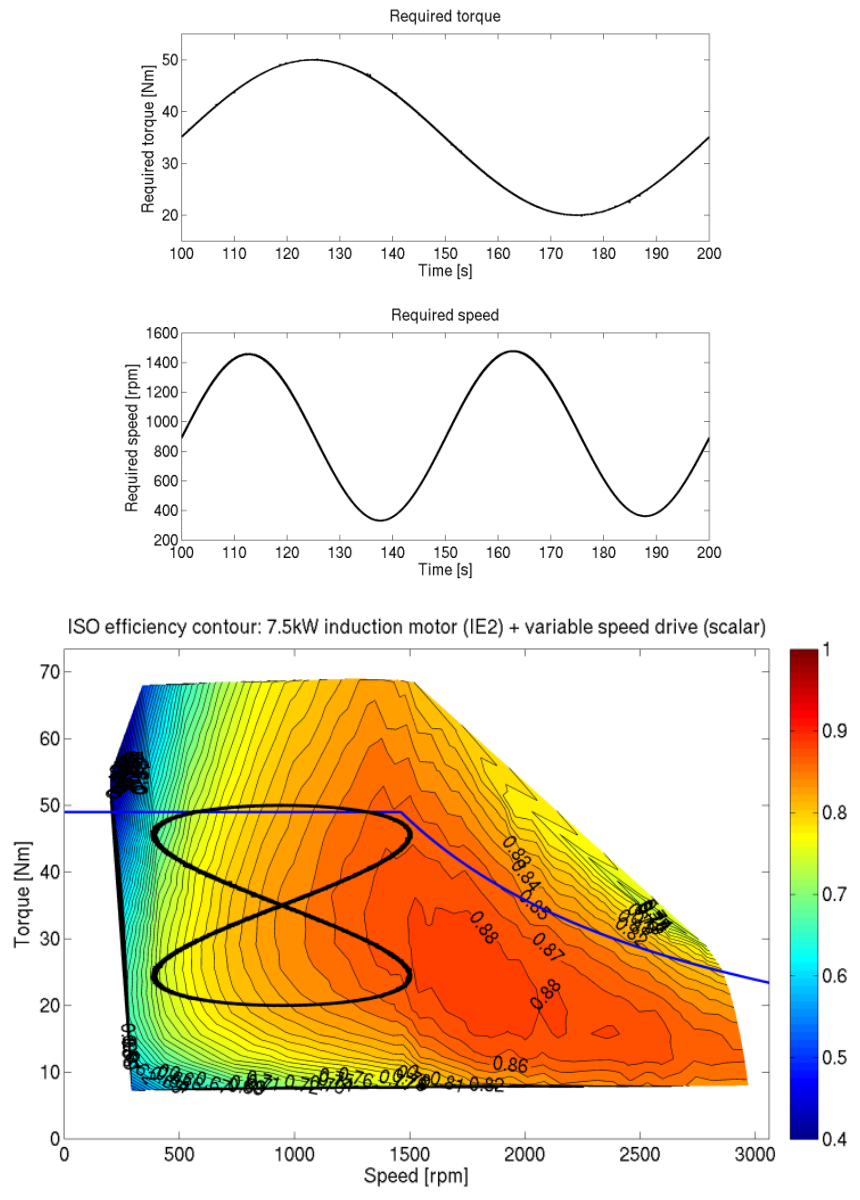

Fig. 4. Example of a continuously varying torque-speed trajectory. The upper two parts show the desired torque and speed respectively as a function of time (during a period of 100s). In this example, the frequency of the varying torque is $0.01 \mathrm{~Hz}$, while the frequency of the varying speed is $0.02 \mathrm{~Hz}$. The lowest part of the figure shows the desired torque-speed trajectory projected on the efficiency contour of the $7.5 \mathrm{~kW}$ test motor.

\section{B. Torque correction}

The measured speed and load torque do not correspond exactly to the demanded speed and torque:

- Speed: the measured speed deviates slightly from the demanded speed when higher load torques are applied, due to the scalar mode of the VSD.

- Torque: the difference between the demanded and the measured torque is mainly caused by the acceleration of the load motor's rotor (not measured by the torque sensor). The acceleration is determined by the frequency of the sinusoidal speed. As the acceleration torque cannot be higher than the maximal torque of the test motor, the frequency of the sinusoidal speed has an upper boundary that depends on the test motor and on the inertia of the load motor's rotor. For this test setup, frequencies of the speed have been applied up to $0.1 \mathrm{~Hz}$ (see section C).

To make the correct comparisons between measured and predicted energy consumption, the measured torque and speed should be used in the calculations. However, the measured torque requires an extra correction before it can be used. The vertical axis of the iso efficiency contour indicates the output torque provided by the test motor. In a static situation (e.g. when the efficiency contour is measured in different static operating points), the output torque of the test motor is the same as the torque measured in the torque sensor. In a dynamic case however (e.g. continuously varying speed trajectories), these torques are different due to the acceleration of the coupling and the test motor's rotor:

$$
T_{\text {test_mot }}=T_{\text {meas }}+J_{\text {rot_coup }} \cdot \alpha
$$

where $\alpha$ indicates the measured acceleration (derived from the measured speed) and $J_{\text {rot_coup }}$ the combined inertia of the test motor's rotor and the coupling. This inertia has been measured separately, so the measured torque can be corrected according to (8) in order to obtain the real motor torque to be used in the calculations.

\section{Parameters of the measured trajectories}

Six trajectories have been measured. The parameters of the sinusoidal speed and torque for each trajectory are summarized in table I.

TABLE I

DATA OF THE SINUSOIDAL SPEED AND TORQUE FOR THE DIFFERENT MEASUREMENTS

\begin{tabular}{|c|c|c|c|c|c|c|c|}
\hline \multicolumn{2}{|c|}{$\begin{array}{c}\text { Measurement } \\
\text { nr. }\end{array}$} & 1 & 2 & 3 & 4 & 5 & 6 \\
\hline \multirow{3}{*}{$\begin{array}{l}\mathrm{T} \\
\mathrm{o} \\
\mathrm{r} \\
\mathrm{q} \\
\mathrm{u} \\
\mathrm{e}\end{array}$} & $\begin{array}{c}\text { Frequency } \\
{[\mathrm{Hz}]}\end{array}$ & 0.01 & 0.002 & 0.05 & 0.02 & 0.004 & 0.1 \\
\hline & $\begin{array}{l}\text { Amplitude } \\
\text { [Nm] }\end{array}$ & 15 & 15 & 10 & 10 & 10 & 5 \\
\hline & $\begin{array}{l}\text { Mean } \\
{[\mathrm{Nm}]} \\
\end{array}$ & 35 & 35 & 40 & 30 & 30 & 35 \\
\hline \multirow{3}{*}{$\begin{array}{l}\mathrm{S} \\
\mathrm{p} \\
\mathrm{e} \\
\mathrm{e} \\
\mathrm{d}\end{array}$} & $\begin{array}{c}\text { Frequency } \\
{[\mathrm{Hz}]}\end{array}$ & 0.02 & 0.004 & 0.1 & 0.01 & 0.002 & 0.05 \\
\hline & $\begin{array}{l}\text { Amplitude } \\
\text { [rpm] }\end{array}$ & 555 & 555 & 555 & 630 & 630 & 630 \\
\hline & $\begin{array}{l}\text { Mean } \\
{[\mathrm{rpm}]}\end{array}$ & 945 & 945 & 945 & 1020 & 1020 & 1020 \\
\hline \multicolumn{2}{|c|}{$\begin{array}{c}\text { Approximate } \\
\text { duration }[\mathrm{s}]\end{array}$} & 2700 & 2700 & 2700 & 2000 & 2000 & 2000 \\
\hline
\end{tabular}

For measurements 1, 2 and 3, the frequency of the speed is always twice the frequency of the torque, resulting in Lissajous figures similar to the one in Fig. 4. For measurements 4,5 and 6 , the frequency of the torque is always twice the frequency of the speed, resulting in a different Lissajous figure. Measurements 2 and 5 are rather slow, while 3 and 6 are faster (higher frequencies). Measurement 3 has the highest frequency for the speed, which corresponds to the limitations of the test bench as mentioned before (max. acceleration $37 \mathrm{rad} / \mathrm{s}^{2}$ ).

The trajectory of measurement 1 is the one that has been shown in Fig. 4. The figure shows the demanded trajectory, but the measured and corrected trajectories deviate only slightly. In measurement 3, however, the difference between 
the demanded and corrected trajectories is considerably higher, due to the higher frequency of the varying speed (and therefore the higher acceleration torque).

\section{Temperature}

The efficiency map of the $7.5 \mathrm{~kW}$ test motor had been measured at the motor's rated operating temperature $\left(67^{\circ} \mathrm{C}\right)$, allowing a deviation of $+/-5^{\circ} \mathrm{C}$.

For the measurements of the trajectories, the motor was first running at rated conditions, until this rated temperature was reached, before starting the trajectory measurement. During measurements 1,2 and 3, the temperature was at first increasing further up to $69^{\circ} \mathrm{C}$ and then slowly decreasing to $64^{\circ} \mathrm{C}$ at 2700 s. During measurements 4,5 and 6 , the temperature also increased at first to $69^{\circ} \mathrm{C}$ and then slowly decreased to $62^{\circ} \mathrm{C}$ at $2000 \mathrm{~s}$. The faster temperature decrease of measurements 4,5 and 6 can be explained by the higher average speed and the lower average torque. However, for all the measurements, the temperature remained within the $5^{\circ} \mathrm{C}$ margin with respect to the rated operating temperature.

\section{E. Measurement results}

The next three figures illustrate the results for measurement 1 .

Fig. 5 compares (a) the measured mechanical power, (b) the measured electrical power and (c) the calculated electrical power during two complete successive runs of the trajectory. Based on this figure, there is only little difference between measured and predicted electrical power consumption. Fig. 6 on the other hand compares the evolution of (a) the produced mechanical energy, (b) the measured electrical energy consumption and (c) the calculated electrical energy consumption during 2700s (or 27 cycles of the complete trajectory). It shows that the measured energy consumption is slightly higher than the calculated consumption. To have a more accurate idea of this difference, the ratio of the calculated and measured electrical energy consumption is plotted in Fig. 7. It shows that the ratio is all the time around $98 \%$, which means there is about $2 \%$ error on the calculation. This small error can be due to small inaccuracies during the measurement of the efficiency map or during the trajectory measurement (or during both).

The plots for the 5 other measurements are similar to the ones shown for measurement 1, meaning that for each measurement, there is hardly a noticeable difference between the measured and the calculated electrical power, and the error on the energy prediction has the same order of magnitude (about 2\%). This is summarized in table II.

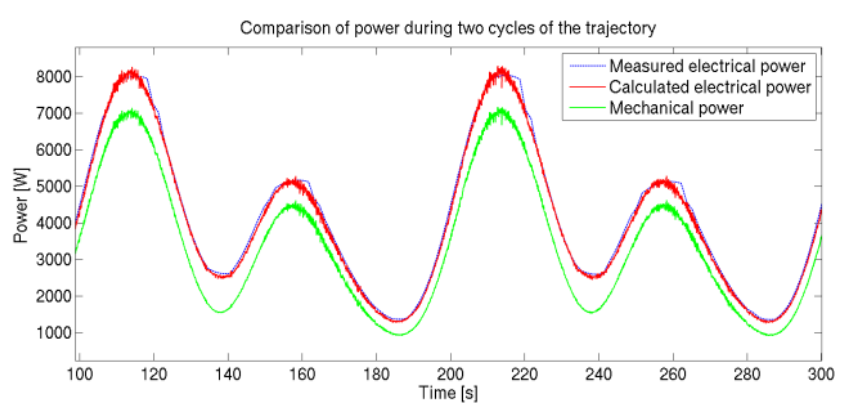

Fig. 5. Comparison of the measured mechanical power, the measured electrical power consumption and the calculated electrical power consumption during 2 cycles of the trajectory in measurement 1 .

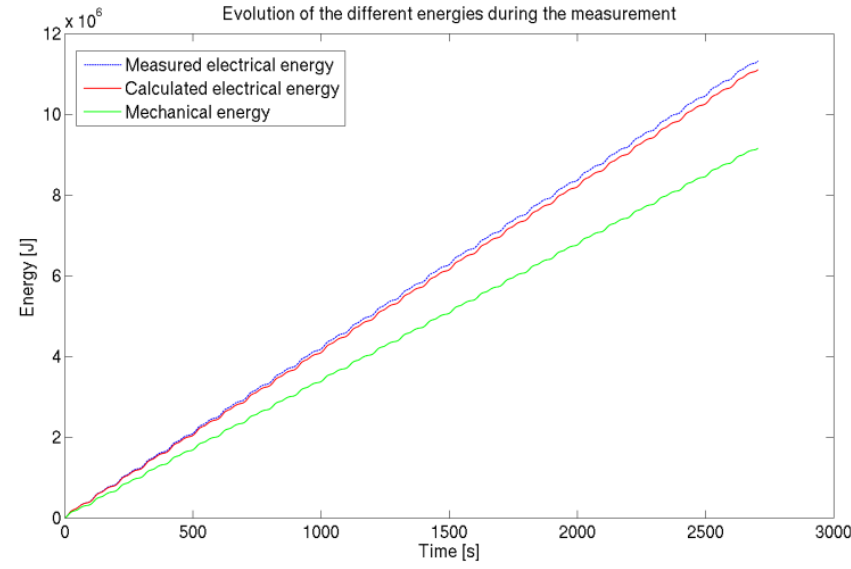

Fig. 6. Evolution of the measured mechanical energy, the measured electrical energy consumption and the calculated electrical energy consumption during measurement 1

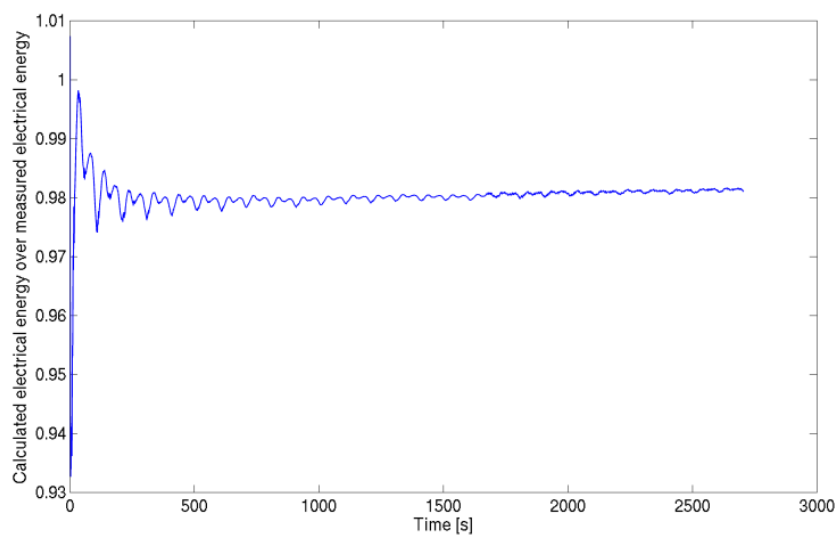

Fig. 7. Ratio of the calculated electrical energy consumption and the measured electrical energy consumption during measurement 1 .

TABLE II

RATIO OF CALCULATED ELECTRICAL ENERGY AND MEASURED ELECTRICAL ENERGY FOR EACH MEASUREMENT AFTER 2000S

\begin{tabular}{|c|c|c|c|c|c|c|}
\hline Measurement nr. & 1 & 2 & 3 & 4 & 5 & 6 \\
\hline $\begin{array}{c}\text { calc. elec. energy / } \\
\text { meas. elec. energy } \\
{[\%]}\end{array}$ & 98.1 & 98.3 & 97.4 & 97.4 & 97.5 & 97.8 \\
\hline
\end{tabular}

The error is small enough to conclude that the predicted energy consumption can effectively be used as an approximation of the real energy consumption during a continuously varying trajectory. Moreover, as far as frequencies are concerned that are allowed by the setup of Fig. 3, there does not seem to be a noticeable effect of the dynamics on the accuracy of the prediction, although a statically measured contour has been used.

With respect to the temperature, no effects were noticed on the measurement results during the small variations described in section D.

\section{VERIFICATION FOR TRAJECTORIES CONSISTING OF A SEQUENCE OF DISCRETE LOAD POINTS}

\section{A. Measurement setup}

The second measurement campaign was performed on a different test bench, but the setup is similar to the one explained in Fig. 3. 
The test motor for this case was a commercial $4 \mathrm{~kW}$ IE1 induction motor with a commercial VSD in direct torque control mode. The applied trajectory is shown in Fig. 8 and represents a number of successive speed-torque set points.

\section{B. No torque correction needed}

For the calculation of the predicted energy consumption during this trajectory, the acceleration from one set point to the next is assumed to be instantaneous, and the inertia torque is neglected (and therefore also the acceleration energy). Comparing the measured and calculated energy consumption will verify whether these assumptions are valid.

\section{Measurement results}

Table III shows the details of the set points of the trajectory in Fig. 8. It also shows the efficiency value for each of these set points (derived from the motor system's iso efficiency contour).

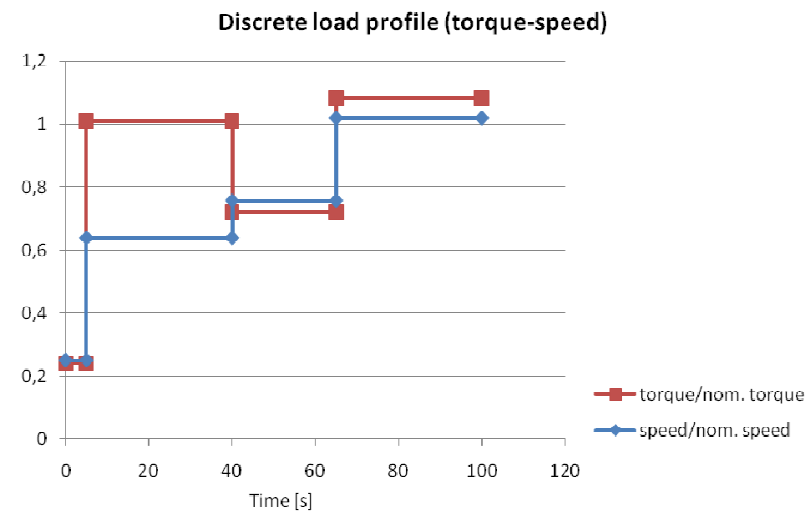

Fig. 8. Discrete torque-speed trajectory. The nominal speed for this motor is $1500 \mathrm{rpm}$, and the nominal torque is $26.62 \mathrm{Nm}$.

TABLE III

DETAILS OF THE SET POINTS OF THE DISCRETE LOAD TRAJECTORY, INCLUDING THE EFFICIENCY OF THE MOTOR SYSTEM IN EACH POINT

\begin{tabular}{|c|c|c|c|}
\hline $\begin{array}{c}\text { Start time of } \\
\text { set point }[\mathrm{s}]\end{array}$ & $\begin{array}{c}\text { Torque } \\
{[\mathrm{Nm}]}\end{array}$ & $\begin{array}{c}\text { Speed } \\
{[\mathrm{rpm}]}\end{array}$ & $\begin{array}{c}\text { Efficiency } \\
{[\%]}\end{array}$ \\
\hline 0 & 6.7 & 373 & 56.9 \\
\hline 5 & 29.2 & 956 & 76.3 \\
\hline 40 & 19.5 & 1134 & 79.0 \\
\hline 65 & 29.2 & 1528 & 76.5 \\
\hline 100 & 0 & 0 & -- \\
\hline
\end{tabular}

Using the equations described in section II.B, the calculated electrical energy consumption during this trajectory amounts to $117.91 \mathrm{Wh}$, while the measured value is $118.04 \mathrm{Wh}$. The difference is only $0.13 \mathrm{Wh}$ or $0.1 \%$ of the measured energy consumption, which is very accurate and indicates the feasibility of the method to predict electrical energy consumption for discrete load trajectories.

\section{CONCLUSION}

This paper describes a method to predict the electrical energy consumption of a motor system (motor and VSD) for a given varying torque-speed trajectory. Based on this prediction, different motor systems could be compared for a specific application in order to determine the most efficient one. The feasibility and accuracy of the calculation method has been evaluated by measurements for both discrete load trajectories and continuously varying trajectories. For both measurements, the error is sufficiently low to approve the methodology.

\section{ACKNOWLEDGMENT}

The research described in this paper has been the result of a fruitful collaboration between three research institutes: FMTC, ELECTA (ESAT) and Howest.

\section{REFERENCES}

Periodicals:

[1] S.S. Williamson, S.M. Lukic and A. Emadi, "Comprehensive Drive Train Efficiency Analysis of Hybrid Electric and Fuel Cell Vehicles Based on Motor-Controller Efficiency Modeling," IEEE Transactions on Power Electronics, 21(3), pp. 730-740, May 2006

Technical Reports:

[2] R. Belmans, F. Vergels, M. Machiels, J. Driesen, B. Collard, L. Honóri, M.H. Laurent, H. Zeinhofer and M.A. Evans, "Electricity for more efficiency: Electric technologies and their energy savings potential," Eurelectric \& UIE, Ref:2004-440-0002, July 2004

[3] H. De Keulenaer, R. Belmans, P. Radgen and A.T. de Almeida, "Energy Efficient Motor Driven Systems... can save Europe 200 billion $\mathrm{kWh}$ of electricity consumption and over 100 million tons of greenhouse gas emissions a year," Brussels, Belgium: European Copper Institute, 2004.

[4] R.H. Staunton, C.W. Ayers, L.D. Marlino, J.N. Chiasson and T.A. Burress, "Evaluation of 2004 Toyota Prius Hybrid Electric Drive System." Oak Ridge National Laboratory, Technical Report ORNL/TM-2006/423, May 2006.

Papers Presented at Conferences (Unpublished):

[5] W. Deprez, J. Lemmens, D. Vanhooydonck, W. Symens, K. Stockman, S. Dereyne and J. Driesen, "Iso Efficiency Contours as a Concept to Characterize Variable Speed Drive Efficiency," submitted to ICEM '10: International Conference on Electrical Machines, Rome, Italy, 2010

[6] K. Stockman, S. Dereyne, D. Vanhooydonck, W. Symens, W. Deprez and J. Lemmens, "Iso Efficiency Contour Measurement Results for Variable Speed Drives," submitted to ICEM '10: International Conference on Electrical Machines, Rome, Italy, 2010

\section{BIOGRAPHIES}

Dirk Vanhooydonck received the M.Sc. degree in mechanical engineering, option mechatronics (1999) and the Ph.D. in applied sciences, (2007), both from the Katholieke Universiteit Leuven. Currently he is involved at the Flanders' Mechatronics Technology Centre (FMTC) in projects dealing with energy efficiency of high-productivity machines.

Wim Symens graduated in 1999 from the Katholieke Universiteit Leuven as a mechanical engineer, option mechatronics and obtained the $\mathrm{PhD}$ degree in mechanical engineering for the same university in 2004. After that, he started at FMTC as responsible for FMTC's "Highproductivity Machines" research program.

Wim Deprez received the M.Eng. degree in electromechanical engineering and material sciences from the Group $\mathrm{T}$, University College Leuven, Belgium. In 2002 and 2008 respectively, he received the M.Sc.

Eng. degree in electromechanical engineering and the Ph.D. degree in electrical engineering from the K.U. Leuven.

Joris Lemmens received the M.Eng. degree in electromechanical engineering in 2008 from the KHLim University College, Diepenbeek, Belgium.

Kurt Stockman received his Master degree in electrotechnics from Provinciale Hogeschool West-Vlaanderen, Kortrijk, Belgium in 1994 and the Ph.D. degree an Katholieke Universiteit Leuven, in 2003. He is currently professor at University College Howest, Kortrijk, Belgium. His research interests include control of electrical machines, energy efficiency and reliability of adjustable speed drives.

Steve Dereyne received his Master degree in electrotechnics from Provinciale Hogeschool West-Vlaanderen, Kortrijk, Belgium in 2001. He is currently assistant at University College Howest, Kortrijk, Belgium. His research interests include motortesting, energy efficiency and design of electrical LV-grids. 